\title{
Sport Profile of the Junior Male Kwa-Zulu Natal Provincial Soccer Team, South Africa
}

\author{
By Terry J. Ellapen* \\ Senthil Narsigan ${ }^{\dagger}$ \\ Sumaya Abrahams \\ Hendrik J. Van Heerden •
}

To document the prevalence of soccer related musculoskeletal pain and the exercise performance of the male KZN provincial junior male soccer team. Eighteen players' underwent kinanthropometric, exercise physiological performance assessments and a musculoskeletal pain questionnaire appraisal. The kinanthropometric characteristics measured were body mass, stature and skinfold measurements. The exercise physiological performance profile constituents were resting heart rate, blood pressure, flexibility, muscle strength and endurance, explosive strength, agility and aerobic capacity. Plantar and dorsi-flexion, quadriceps angles and hip extension constituted the flexibility tests. The players abdominal and upper body muscle strength and endurance were measured by the one minute sit-up and one-minute press-up tests respectively. Explosive strength was measured using the vertical jump protocol. Subjects completed a $10 \mathrm{~m}$ agility t-test and 20 multi-stage fitness test. Out of the 18 players who answered the questionnaire, $72.22 \%$ experienced soccer related musculoskeletal pain indicating the knee (42.86\%), ankle (28.57\%), hip (21.43\%), and vertebrae $(7.14 \%)$ to be most prevalent $(\mathrm{p}<0.05)$. The cohort's mean age, body mass, stature, body mass index and percent body fat were $14.33 \pm 0.69$ years, $53.28 \pm 7.59 \mathrm{~kg}, 1.63 \pm 0.08 \mathrm{~m}, 20.04 \pm 1.48 \mathrm{~kg} / \mathrm{m}^{2}$ and $5.55 \pm$ $2.23 \%$ respectively. The mean resting heart rate was $59.78 \pm$ $12.74 \mathrm{bpm}$ and the derived MAP and RPP were $90.88 \pm 18.45 \mathrm{mmHg}$ and7651.84 respectively. The players' push-up $(36.44 \pm 7.53$ rep/min.) and vertical jump (32.42 \pm 0.27$)$ scores were below the norm. The subjects' flexibility, abdominal strength and endurance, agility and aerobic capacity were within the normative ranges respectively. The soccer players have sustained musculoskeletal pain over the last 12 months. The players need to adhere to a regular strength training regime to enhance their sport performance as well as to serve as a protective mechanism against musculoskeletal injury.

* Lecturer, University of Kwa Zulu Natal, South Africa.

Lecturer, University of Kwa Zulu Natal, South Africa.

${ }^{\ddagger}$ University of Kwa Zulu Natal, South Africa.

- Professor, University of Kwa Zulu Natal, South Africa. 


\section{Introduction}

Soccer is the most popular sport in the world, having approximately 40 million participants playing the game (Hoy et al. 1992). Since the 1970's organized soccer leagues for children and adolescents have grown rapidly. The growth of soccer participation globally has been due to (i) the relative simplicity of the game, (ii) the relative lack of expense of the equipment and uniforms, (iii) the relative ease of accessibility to play, and (iv) the belief that soccer is a "safer" game for children and adolescents to play (Metzl et al. 1998). In South Africa, the school soccer leagues serves as the reservoir of young soccer talent, from which the provincial selectors derive their provincial teams. The KZN junior soccer team was the strongest among the 11 South African provincial teams who competed at the 2011 Annual South African Youth Sport Tournament.

Sport profiling of soccer teams is a common practise aimed to improve sport performance as well as decrease the incidence of musculoskeletal injury (Bangsbo, 1998). The physiological demands of soccer require the players to be adept in the following conditioning components, aerobic, anaerobic, flexibility, muscle strength and endurance and agility (Ekblom, 1986; Reilly et al. 2003). Laboratory and field tests serve as instruments for coaches and exercise scientists to establish the fitness, physiological strength and weaknesses of the players, prevalence of musculoskeletal injury and risk of musculoskeletal injury.

Musculoskeletal injuries are common among soccer players (Hagglund et al. 2005; Fuller et al. 2006). The fundamental problem concerning international epidemiological investigations is the inconsistent definition of musculoskeletal injury. Hagglund et al. (2005) proposed that the prevalence of musculoskeletal injury can be established, if the following has being documented; anatomical site of musculoskeletal pain, symptoms of the associated pain, type of pain, intensity of pain and the duration that the musculoskeletal pain sensation rendering the person incapacitated or unable to play soccer. The high prevalence of injury among players has been attributed to an ever increasing number of people playing the game (Hagglund et al. 2005; Fuller et al. 2006). At secondary school level, the inter-scholastic competition among the school leagues has increased the prevalence of musculoskeletal injury (Schmidt-Olsen et al. 1991). The prevalence of soccer musculoskeletal injury has steadily increased from $16 \%$ (recreational level) to $46 \%$ (club level) among adolescent players primarily due to the level of competition (Goldberg et al. 1988). Soccer players sustain a greater prevalence of musculoskeletal injury to their lower extremities (85\%) as compared to their upper extremities (15\%) (Chesham, 1997). The most prevalent anatomical sites of soccer musculoskeletal injury are the knee, ankle, femur and head. The predisposing mechanisms of musculoskeletal injury are direct physical trauma from collision with other players, poor landing after jumping, inadequate warm-up, rapid rotational movement and poor muscle flexibility and muscle strength (Ekstrand \& Gillquist, 1983; Nielsen et al. 1989). 
The aim of this study was to document the nature of the common soccer musculoskeletal injury and exercise performance profile of the KZN junior male soccer team. There has been two investigations which documented the exercise performance profile of senior South African professional club level male soccer players (Green, 1992; Clark 2007), however there has being no published literature on the prevalence of musculoskeletal injury and exercise performance measures of junior South African players. This information will contribute significantly to the existing body of knowledge in an attempt to enhance soccer performance and prevent musculoskeletal injury.

\section{Methods}

The Kwa-Zulu Natal Sport Academy recruited the expertise of the University of Kwa-Zulu Natal sport scientists to determine the sport profile of their junior male soccer team. Eighteen players' completed kinanthropometric and exercise performance assessments as well as a musculoskeletal injury questionnaire appraisal. The kinanthropometric characteristics measured were body mass, stature and 7-site skinfold measurements according to the ACSM's Resource Manual's Guidelines for Exercise Testing and Prescription (ACSM 2001). The exercise performance profile constituents were resting heart rate, blood pressure, flexibility, muscle strength and endurance, explosive strength, agility and aerobic capacity. Plantar and dorsi-flexion and quadriceps angles constituted the flexibility test battery which was assessed according to the respective protocols described in Houglum (2006). The players completed the one minute sit-up and press-up tests which assessed the abdominal and upper muscle strength and endurance respectively. Explosive strength was measured using the vertical jump protocol. Players completed a $10 \mathrm{~m}$ agility T-test and 20 multi-stage fitness test. The order of the test battery was as follows; musculoskeletal injury questionnaire appraisal, resting cardiovascular measures, kinanthropometric, flexibility and exercise performance measures.

An interview was served to record the soccer player's exercise history and prevalence of musculoskeletal injury within the last 12 months. The players' history of soccer musculoskeletal injury was gathered by employing a selfreport musculoskeletal injury questionnaire adapted from van Heerden (1996) and the Kee and Seo Pain Rating Scale, (Kee \& Seo, 2007). Players were requested to indicate only soccer musculoskeletal injury, not musculoskeletal injury contracted from other sport and/or recreational activities. The definition of musculoskeletal injury used in this study was defined as any sensation of distress to the musculoskeletal system ranging from no pain to worst pain ever experienced, which inhibited the soccer player from engaging in soccer for a minimum duration of 24 hours (adapted from van Heerden 1996). Pain was employed in the questionnaire because it is a discernible symptom of musculoskeletal injury.

After the interview, resting heart rate and blood pressure measures were recorded. All players were seated for duration of five minutes before resting 
heart rate and blood pressure was measured with a Welch-Allyn electronic blood pressure monitor according to ACSM's Resource Manual's Guidelines for Exercise Testing and Prescription (ACSM 2001). These resting cardiovascular values were used to compute the participant's resting rate pressure product (RPP) and mean arterial pressure (MAP). RPP is the product of systolic blood pressure and heart rate which is the work index of the myocardium that is responsible for the heart's contractile efficiency (Kitamura, 1972). MAP represents the average force exerted by the blood against the resistance within the arterial vessels within a single cardiac cycle.

The KZN male soccer team consisted of 18 players all of whom participated in the study, thereby indicating $100 \%$ compliance of this specific homogenous population. The inclusion criteria of the study were; all participants had to belong to KZN provincial male junior soccer team and parental voluntarily informed consent. The statistical rule of thumb pertaining to the minimum percentage of subjects participating in a study, yielding power of significance of the findings of the study is $30 \%$ of the population as suggested by Terre-Blanche et al. (2008), which this study's sample exceeds. The sample size is consistent with contemporary literature from other international epidemiological and exercise performance profile studies (Apor 1988, n=13, Faina et al. 1988, n=6, Green 1992, n=10, Puga et al. 1993, n=13 \& Casajus 2001, $\mathrm{n}=12$ ).

Descriptive statistics which included the mode, mean, frequency, percentages and inferential statistics comprising of correlations, $t$-tests and chisquare tests $(p \leq 0.05)$ were employed in the statistical analysis. The Levene's test was used to assess the homogeneity variance which revealed unequal variance. A two-tailed T-test adjusted for unequal variance was employed to assess the statistical comparative significance of the injured versus the noninjured players. The probability level was set at 0.05 .

\section{Results}

The results will be presented in the following order; demographic details (Table 1), kinathropometric measures (Table 2), cardiovascular measures (Table 3), musculoskeletal injury appraisal and performance results (Table 6). The majority of the players were; African (77.7\%) followed by Whites $(11.1 \%)$, Coloureds $(5.5 \%)$ and Indians $(5.5 \%)$.

\section{Musculoskeletal Injury Appraisal}

Of the 18 players who answered the questionnaire, $72.2 \%$ experienced soccer musculoskeletal injury with the knee being most vulnerable (42.8\%) followed by ankle (28.5\%), hip (21.4\%), and vertebrae $(7.1 \%)(\mathrm{p}<0.05)$. Players who sustained knee musculoskeletal injury had a mean quadriceps angles which significantly differed from non-injured players $(\mathrm{p}<0.05)($ Table 2). 
Table 1. Demographic Details of the Cohort $(n=18)$

\begin{tabular}{|c|c|}
\hline Demographic variables & Mean \pm Standard deviation \\
\hline Age (years) & $14.3 \pm 0.6$ \\
\hline Body mass $(\mathrm{kg})$ & $53.2 \pm 7.5$ \\
\hline Stature $(\mathrm{m})$ & $1.63 \pm 0.08$ \\
\hline Body mass index $\left(\mathrm{kg} / \mathrm{m}^{2}\right)$ & $20.0 \pm 1.4$ \\
\hline Percentage body fat $(\%)$ & $5.5 \pm 2.2$ \\
\hline
\end{tabular}

Table 2. Kinanthropometric Measures of the Cohort $(n=18)$

\begin{tabular}{|c|c|c|}
\hline Performance variables $(\mathbf{n}=\mathbf{1 8})$ & Right & Left \\
\hline Plantar flexion $\left({ }^{\circ}\right)$ & $33.94 \pm 10.78$ & $34.11 \pm 10.78$ \\
\hline Dorsi-flexion $\left(^{\circ}\right)$ & $21.61 \pm 7.49$ & $23.89 \pm 7.75$ \\
\hline Quadriceps angle $\left(^{\circ}\right)$ & $9.38 \pm 1.33$ & $7.05 \pm 2.89$ \\
\hline
\end{tabular}

Table 3. Cardiovascular Measures of the Cohort $(n=18)$

\begin{tabular}{|c|c|}
\hline Cardiovascular measures & Mean \pm Standard deviation \\
\hline Resting heart rate $(\mathrm{bpm})$ & $59.7 \pm 12.7$ \\
\hline MAP $(\mathrm{mmHg})$ & $90.8 \pm 18.4$ \\
\hline RPP & 7651.8 \\
\hline
\end{tabular}

Table 4. Comparison of the Quadriceps Angles of the Players who Sustained Knee Injuries and Non-Injured Players

\begin{tabular}{|c|c|c|c|}
\hline Injured $(\mathrm{n}=8)$ & Non-injured $(\mathrm{n}=10)$ & $\mathrm{p}$-value & Significance $(\mathrm{p}<0.05)$ \\
\hline $11.1 \pm 2.1^{\mathrm{o}}$ & $7.6 \pm 2.1^{\mathrm{o}}$ & 0.007 & $\mathrm{p}<0.05$ \\
\hline
\end{tabular}

Table 5. Comparison of Plantar and Dorsi-Flexion Angles of Players who Sustained Ankle Injuries and Non-Injured Players

\begin{tabular}{|c|c|c|c|c|}
\hline $\begin{array}{c}\text { Range of } \\
\text { motion }\end{array}$ & Non-injured & Injured & $\mathrm{p}$-value & $\begin{array}{c}\text { Significance } \\
(\mathrm{p}<0.05)\end{array}$ \\
\hline $\begin{array}{c}\text { Plantar } \\
\text { flexion }\end{array}$ & $34.5 \pm 10.4$ & $32.7 \pm 11.4$ & 0.6 & $\mathrm{p}>0.05$ \\
\hline Dorsi-flexion & $23.6 \pm 7.2$ & $19.7 \pm 7.5$ & 0.1 & $\mathrm{p}>0.05$ \\
\hline
\end{tabular}

Table 6. Players' Mean Exercise Performance $(n=18)$

\begin{tabular}{|c|c|}
\hline Exercise performance variables & Mean performance \\
\hline One minute sit-ups (repetitions/min.) & $47.28 \pm 5.56$ \\
\hline One minute press-up (repetitions/min.) & $36.44 \pm 7.53$ \\
\hline 10m agility T-test (seconds) & $11.95 \pm 0.49$ \\
\hline Vertical jump (cm) & $32.42 \pm 6.12$ \\
\hline 25m Run sprint (seconds) & $4.24 \pm 0.27$ \\
\hline 20 multi-stage fitness (ml/kg/min) & $60.79 \pm 18.85$ \\
\hline
\end{tabular}

The Kee and Seo Pain Rating Scale which ranged from 1-5, (1 being no pain and 5 being worst pain ever experienced) was used to determine the intensity of musculoskeletal pain experienced by the players. A score of 3 (moderate pain intensity) was rated the most prevalent $(38.4 \%)(p<0.01)$ followed by a rating score of 5 (worst pain ever experienced) (23.0\%) 
$(\mathrm{p}<0.05)$, rating score of 1 (no pain) $(15.3 \%)(\mathrm{p}<0.05)$, rating score of 4 (severe pain) $(15.3 \%)(\mathrm{p}<0.05)$ and a rating score of 2 (mild pain) $(7.6 \%)$. The most common symptoms of musculoskeletal pain reported was dull aching (78.5\%) $(\mathrm{p}<0.01)$ followed by sharp $(7.1 \%)$, burning $(7.1 \%)$ and swelling $(7.1 \%)$. The predisposing mechanisms producing soccer musculoskeletal injury were: direct physical trauma - collision with another player, rapid rotational movement, and poor landing. According to the cohort $68.7 \%$ sort no medical treatment post injury, however $18.7 \%$ consulted general practioner, while $6.2 \%$ consulted orthopaedic surgeon and physiotherapist respectively. The participants' practised soccer an average of 10.6 months per year $( \pm 1.3)$ and 4.0 days per week $( \pm 0.8)$. Soccer exposure included practise, training sessions and game time.

There was no statistically significance between the agility T-test performance of players who sustained ankle and non-injured players $(p>0.05)$. Similarly no statistical significance was found between the agility $\mathrm{T}$-test performance of knee injured and non-injured players' $(p>0.05)$.

\section{Discussion}

The results will be discussed in the following order musculoskeletal injury appraisal, cardiovascular measures, kinathropometry, flexibility and exercise performance variables.

\section{Musculoskeletal Injury Appraisal}

Among the 18 players surveyed, $72.2 \%$ experienced soccer musculoskeletal injury $(\mathrm{p}<0.05)$ which correspond with previous literature (Metzl et al. 1998; Hagglund et al. 2005). The most prevalent anatomical sites that experienced musculoskeletal injury were knee and ankle. Players who sustained knee injury had larger quadriceps angles compared to non-injured players which are clinically significant indicating genu valgum and knee extensor mechanism dysfunction (Arendt et al. 1995; Bordal et al. 1997).

The players who experienced musculoskeletal ankle injury ran slower agility T-test completion times compared to the other players who did not sustain musculoskeletal ankle injury ( $p>0.05)$. Efficient agility requires optimal movement of the ankle in the sagittal and transverse planes. Ankle injuries limit sagittal and transverse movements thereby producing slower agility completion times. Agility is the ability to change direction of the body rapidly and is a result of a combination of muscle strength, speed, balance and agility (Draper et al. 1985). The fast pace of competitive soccer requires players to possess good agility.

The cohort reported that the most prevalent type of pain experienced was dull aching. Prentice (2004) and Brukner et al. (2006) identify dull aching sensations as muscle pain. Subjective pain rating according to the Kee and Seo Pain Rating Scale indicates the prevalence of the musculoskeletal pain experienced by the cohort were as follows; moderate pain followed by worst 
pain ever experienced. Combining the evidence of the anatomical site of pain, the type of pain and the intensity of pain, is indicative of musculoskeletal pathology (as suggested by Hagglund et al. 2005; Fuller et al. 2006). The predisposing mechanisms of musculoskeletal injury were collision with other players, rapid rotational movement and poor landing who are renowned aetiological factors producing soccer musculoskeletal injury (Ekstrand \& Gillquist, 1983; Nielsen et al. 1989). A concerning factor is the lack of medical treatment secured by players after sustaining musculoskeletal injury.

\section{Cardiovascular Measures}

The following resting cardiovascular measures, heart rate and blood pressure provide clinical insight to health and efficiency of the cardiovascular system. Wilmore et al. (2007) reported that individuals with a resting heart rate measure of $72 \mathrm{bpm}$ are considered healthy, whilst individuals with resting values higher than $100 \mathrm{bpm}$ (tachycardia) are at a higher risk of cardiac arrest and are considered unhealthy. Conversely people, with heart rates below 60 bpm (bradycardia) are considered very fit and exhibit low risk of cardiac arrest (Kent 2005; McArdle et al. 2007). However, the general rule of thumb being, the lower the resting heart rate the fitter and healthier the athlete (McArdle et al. 2007). The maintained above 6000 over-works the heart muscle (Hagberg 1983 \& Durnstine et al. 2003). The players' RPP was above 6000 due to their elevated systolic players resting heart rates (RHR) were within the range of 65$75 \mathrm{bpm}$ indicating efficient chronotropic function.

Epidemiologists agree that resting RPP that is continuously blood pressure. However, participants' MAP values' fell within the normative range, indicating limited resistance to blood flow in the arteries (Paffenbarger 1993; Gutin 1996).

\section{Kinanthropometry}

BMI is an elementary mathematical equation commonly used to describe people's body composition (Kent 2005). ACSM (2001) considers a person having a BMI less than $19.99 \mathrm{~kg} / \mathrm{m}^{2}$ as being underweight, $20.0-24.99 \mathrm{~kg} / \mathrm{m}^{2}$ as healthy, whilst $25.0-29.99 \mathrm{~kg} / \mathrm{m}^{2}$ as overweight and obesity from $29.99 \mathrm{~kg} / \mathrm{m}^{2}$. The soccer players' BMI fell within the healthy category, $20.0-24.99 \mathrm{~kg} / \mathrm{m}^{2}$ (ACSM 2001). A critical limitation of the BMI is its generalized description of individuals' body composition. Due to the inherent limitations of BMI, specific anatomical skinfold sites were measured to derive the players percentage body fat. The players' mean percentage body fat were $5.5 \%$ which falls within the age and gender normative ranges. McArdle et al. (2007) proposed that percentage body fat ranging below $10 \%$ is optimal for trained athletes. Inverse relationships were observed between percentage body fat and estimated $\mathrm{VO}_{2}$ max among the players $(\mathrm{r}=0.6)$. McArdle et al (2007) report that regular physical exercise; especially aerobic exercises have both cardio-protective and exercise performance enhancement benefits. Higher $\mathrm{VO}_{2} \max$ values indicate cardiovascular efficiency, which enhances sport performance. The mean 
$\mathrm{VO}_{2} \mathrm{max}$ of elite soccer players has typically reported to range from 55-65 $\mathrm{ml} / \mathrm{kg} / \mathrm{min}$ (Nowacki et al. 1988; Edwards et al. 2003).

\section{Flexibility}

The plantar flexion indicates the extensibility of the anterior muscles whilst dorsi-flexion reveals the extensibility of the posterior muscles which attaches from the tibia and fibula onto the foot. Plantar flexion range varies from $0-45^{\circ}$, whilst dorsi-flexion ranges from $0-20^{\circ}$ (Prentice 2005). Plantar and dorsi-flexion indicates the force couple relationship between the anterior and posterior muscles of the lower limb and foot. The players' plantar flexion measure is within the normative range however their dorsi-flexion is greater than the normative range. This indicates that the posterior muscles are more flexible than the anterior muscles suggesting an abnormal force couple relationship between the anteroposterior muscles of the tibia and foot (which increases the risk of musculoskeletal injury to the tibia, fibula, foot and ankle).

\section{Exercise Performance Variables}

The exercise performance variables will be discussed in the following order, muscle strength and endurance, explosive strength, agility and aerobic capacity.

\section{Muscle Strength and Endurance}

Abdominal strength and endurance is important for core stability. A strong core is essential for the efficient transmission of force from the foot to upper body in the closed kinetic chain (Dominguez 1983). The players' mean abdominal muscle strength and endurance score fell within the normative range (44-60 repetitions per minute, ACSM 2001). Similarly upper body muscle strength and endurance was measured using the one minute press-up test. The players' mean press-up test score receives a rating score of below average. The normative range of the one minute press-up test varies from 47-60 repetitions per minute (which is awarded a rating of good to excellent). This result indicates a need for the players to adhere to strength training regime in an attempt to increase upper body muscle strength and endurance.

\section{Explosive Strength}

The vertical jump test was employed to measure the players' lower limb explosive strength. The players' mean vertical jump score is awarded a rating of below average. This evidence suggests that the players need to improve their muscle strength, which necessitates the adherence to strength training regime. Vertical jumping in the game of soccer is an essential component needed for the motor skill of heading (Svensson et al. 2005).

\section{Aerobic Capacity}

The players' aerobic capacity was indirectly estimated by employing the 20 multi-stage fitness test. The soccer players mean estimated aerobic capacity $(60.79 \mathrm{ml} / \mathrm{kg} / \mathrm{min})$ fell within normative range of elite soccer players (55- 
$65 \mathrm{ml} / \mathrm{kg} / \mathrm{min}$ ) (Nowacki et al. 1988; Edwards et al. 2003). Higher aerobic capacity is an essential conditioning component needed to attain success in the game of soccer.

\section{Conclusion}

The soccer players have sustained musculoskeletal injury over the last 12 months which needs to be rehabilitated by the appropriate medical professional. In addition, the players need to adhere to a regular strength training regime to enhance their sport performance as well as to serve as a protective mechanism against musculoskeletal injury. Further profiling of adolescent soccer players must be conducted to investigate the impact of musculoskeletal injury on sport performance.

\section{Acknowledgement}

The researchers would like to extend their appreciation to following individuals, Dr. R. Naidoo, Mr. C Stow, Mr. MH, Noorbhai, Mr. S Thwala, Miss NA MacRae and Miss J Milne for their assistance during the study.

\section{References}

American College of Sports Medicine (ACSM) (2001). ACSM's Guidelines for Exercise Testing and Prescription. Philadelphia: Lippincott, Williams \& Wilkins.

Apor, P. (1988). Successful formulae for fitness training. Science and Football. London: E \& FN Spon.

Arendt, E., Dick, R. (1995). Knee injury patterns among men and women in collegiate basketball and soccer. Am J Sports Med, 23: 694-701.

Bangsbo, J. (1998). Optimal preparation for the world cup in soccer. Clin Sports Med, 17(4): 698-709.

Bordal, J.M., Arnly, F., Hannestad, B. (1997). Epidemiology of anterior cruciate ligament injuries in soccer. Am J Sports Med, 25: 341-345.

Brukner, P., Khan, K. (2006). Clinical Sports Medicine (3 ${ }^{\text {rd }}$ edition). New York: The McGraw Hill Company

Casajus, J.A. (2001). Seasonal variation in fitness variables in professional soccer players. J Sports Med Phys Fit, 41: 463-467.

Chesham, R.H.D. (1997). Sports related oral injury and mouth guard use among Sheffield school children. Community Dental Health, 14: 25-30.

Clark, J.R. (2007). Positional assessment and physical fitness characteristics of male characteristics of male professional players in South Africa. AJPHERD 13 (4): 453-464. 
Dominguez, R.H. (1982). Total Body Training. East Dundee, IL: Moving Force Systems

Draper, J.A., Lancaster, M.G. (1985). The 505 test: A test for agility in the horizontal plane. Aust J Sc Med Sport, 17; 15-18.

Durstine, J.L., Moore, G.E. (2003). ACSM's Exercise Management for persons with Chronic Diseases and Disabilities. Human Kinetics: New York.

Edwards, A.M., Clark, N., Macfadyen, A.M. (2003). Lactate and ventilator thresholds reflect the training status of professional soccer players where maximum aerobic power is unchanged. J Sports Science Med Phys Fitness, 2: 23-29.

Ekblom, B. (1986). Applied physiology of soccer. Sports Med, 3: 50-60.

Ekstrand, J. \& Gillquist, J. (1983). The avoidability of soccer injuries. Int J Sports Med, 4: 124-128.

Faina, M., Gallozzi, C., Lupo, S., Colli, R. Sassi, R., Marini, C. (1988). Definition of the physiological profile of the soccer player. Science and Football. London: E \& FN Spon.

Fuller, C.W., Ekstrand, J., Junge, A., Andersen, T.E., Bahr, R., Dvorak, J., Hagglund, M., McCrory, P. (2006). Consensus statement on injury definitions and data collection procedures in studies of football (soccer) injuries. Scand J Med Sci Sports, 16: 83-92.

Goldberg, B., Rosenthal, P.P., Robertson, L.S. (1988). Injuries in youth football. Paediatrics, 81: 255-261Hagglund, M., Walden, M., Bahr, R., Ekstrand, J. (2005). Methods for epidemiological study of injuries to professional football players: developing the UEFA model. $\mathrm{Br} J \mathrm{Sp} \mathrm{Med}$, 39: $340-346$.

Green, S. (1992). Anthropometric and physiological characteristics of South Australian soccer players. Aust J Sc Med Sport, 24: 3-7.

Gutin, B. (1996). Physical training, lifestyle, education and coronary risk factors in obese girls. Med Sc Sport and Exerc, 28: 19-23.

Hagberg, J.M. (1983). Effects of 12 months of intense exercise training on stroke volume in patients with coronary artery disease. Circulation, 67: 1194-1199.

Hoy, K., Lindblad, B.E., Terkelsen, C.J. (1992). European soccer injuries. A prospective epidemiological and socioeconomic study. Am J Sp Med, 20: 318-322.

Houglum (2005). Therapeutic exercises for musculoskeletal injuries $\left(3^{\text {rd }}\right.$ edition). Champaign: IL: Human Kinetics

Kee, D., Seo, S.R. (2007). Musculoskeletal disorders among nursing personnel in Korea. Int J Ind Ergon, 37, 207-212.

Kent, M. (2005). Oxford Dictionary of Sports Science and Medicine. Oxford: University Press.

Kitamura, K. (1972). Hemodynamic correlates of myocardial oxygen consumption during upright exercises. Journal of Applied Physiology, 32: 516-522.

McArdle, W.D., Katch, F.I., Katch, V.L. (2007). Exercise Physiology (6 ${ }^{\text {th }}$ ed.). Lippincott, Williams \& Wilkins, Philadelphia: Baltimore. 
Metzi, J.D., Micheli, L.J. (1998). Youth Soccer: An epidemiological perspective. Clin Sports Med. 17(4): 663-673.

Nielsen, A.B., Yde, J. (1989). Epidemiology and traumatology of injuries in soccer. Am J Sports Med, 17: 803-807.

Nowacki, P.E., Cal, D.Y., Buhl, C., Krummelbein, U. (1988). Biological performance of German soccer players (professional and juniors) tested by special ergometry and treadmill methods. Science and Football. Ed: Reilly, T., Lees, A., Davis, K \& Murphy, W.J. 145-157.

Paffenbarger, R.S. (1993). The association between changes in physical activity level and other lifestyle characteristics with mortality among men. N Eng J Med, 328: 538-545.

Prentice, W.E. (2004). Rehabilitation techniques for Sports Medicine and Athletic Training. Champaign, IL: Human Kinetics

Puga, N., Ramos, L., Agostinho, J., Lomba, I., Costa, O., de Freitas, F. (1993). Physical profile of a first division Portuguese professional soccer team. Science and Football. London: E \& FN Spon.

Reilly, T., Doran, D. (2003). Fitness assessment. Science and Soccer. London: Routledge.

Schmidt-Olsen, S., Jorgensen, U., Kaalund, S. (1991). Injuries among young soccer players. Am J Sports Med, 19: 273-275.

Svensson, M. \& Drust, B. (2005). Testing soccer players. J Sports Sc, 23(6): 601-618.

Terre-Blanche, M., Durrheim, K., Painter, D. (2008). Research in Practice. Cape Town: University of Cape Town Press: 50.

Van Heerden, H.J. (1996). Pre-participation evaluation and identification of aetiological risk factors in epidemiology of sports injuries among youths. Doctor of Philosophy. Pretoria: University of Pretoria

Wilmore, J.H., Costill, D.L., Kenney, W.L. (2007). Physiology of Sport and Exercise $\left(9^{\text {th }}\right.$ ed.). Human Kinetics: New York. 
